Article

\title{
Technical Evaluation of Superconducting Fault Current Limiters Used in a Micro-Grid by Considering the Fault Characteristics of Distributed Generation, Energy Storage and Power Loads
}

\author{
Lei Chen ${ }^{1, *}$, Xiude Tu ${ }^{1}$, Hongkun Chen ${ }^{1}$, Jun Yang ${ }^{1}$, Yayi $\mathrm{Wu}^{1}$, Xin Shu ${ }^{2}$ and Li Ren ${ }^{3}$ \\ 1 School of Electrical Engineering, Wuhan University, Wuhan 430072, Hubei, China; \\ kingofnarnia@163.com (X.T.); chkinsz@163.com (H.C.); jyang@whu.edu.cn (J.Y.); wyyhfut@126.com (Y.W.) \\ 2 State Grid Hubei Electric Power Research Institute, Wuhan 430077, Hubei, China; ssshu4948@gmail.com \\ 3 State Key Laboratory of Advanced Electromagnetic Engineering and Technology, \\ Huazhong University of Science and Technology, Wuhan 430074, Hubei, China; renli@mail.hust.edu.cn \\ * Correspondence: stclchen1982@163.com; Tel.: +86-135-1720-5365
}

Academic Editor: João P. S. Catalão

Received: 26 June 2016; Accepted: 19 September 2016; Published: 23 September 2016

\begin{abstract}
Concerning the development of a micro-grid integrated with multiple intermittent renewable energy resources, one of the main issues is related to the improvement of its robustness against short-circuit faults. In a sense, the superconducting fault current limiter (SFCL) can be regarded as a feasible approach to enhance the transient performance of a micro-grid under fault conditions. In this paper, the fault transient analysis of a micro-grid, including distributed generation, energy storage and power loads, is conducted, and regarding the application of one or more flux-coupling-type SFCLs in the micro-grid, an integrated technical evaluation method considering current-limiting performance, bus voltage stability and device cost is proposed. In order to assess the performance of the SFCLs and verify the effectiveness of the evaluation method, different fault cases of a 10-kV micro-grid with photovoltaic (PV), wind generator and energy storage are simulated in the MATLAB software. The results show that, the efficient use of the SFCLs for the micro-grid can contribute to reducing the fault current, improving the voltage sags and suppressing the frequency fluctuations. Moreover, there will be a compromise design to fully take advantage of the SFCL parameters, and thus, the transient performance of the micro-grid can be guaranteed.
\end{abstract}

Keywords: distributed generation (DG); micro-grid; flux-coupling-type superconducting fault current limiter (SFCL); technical evaluation method; short-circuit fault analyses

\section{Introduction}

Due to the increasing penetration of renewable distributed generation units, such as photovoltaic and wind generators, the technical idea of micro-grids has been suggested to make full use of DG [1-6]. In addition, considering the rapid development of computer and digital communication technologies [7-13], the micro-grids may play a crucial role in the future energy internet. A micro-grid is a flexible electrical system being composed of DG units, energy storage and power loads. In most cases, the micro-grid is normally connected to the main network, unless the initial design concept of this micro-grid is the islanded type. When a short-circuit fault happens, the micro-grid may achieve the operation of fault ride through (FRT) or switch to the islanded mode. If the FRT operation is achieved, the micro-grid can continue to purchase power from the main network or sell power to the main network for maximize operational benefits. Once the islanded mode is triggered, the micro-grid should maintain a reliable energy supply to customers using local DG units. Anyhow, during the 
process of the fault feeding, it is crucial to improve the micro-grid's transient performance as much as possible. From this perspective, the technical methods that can alleviate short-circuit current, suppress frequency/voltage fluctuations and strengthen the operational stability of the micro-grid are helpful and useful.

The SFCL can be regarded as one of the best countermeasures to solve the problems related to a short-circuit fault. There are many remarkable merits, including: sub-cycle operation in response to faults; reduced damage at the point of fault; and critical protection of relevant power equipment [14-19]. Currently, some basic research works have been done to promote the application of one or more SFCLs in a micro-grid. In [20], a hybrid-type SFCL is applied in a simplified micro-grid with synchronous DG, and this hybrid-type SFCL's current-limiting performance can be verified. In [21,22], the positioning of resistive-type SFCLs in direct-current (DC) and alternating-current (AC) micro-grids has been preliminarily discussed, and the simulation results imply that the SFCLs should be located in the direct path of current flowing from the DG units and the main network. In [23,24], the cooperative control of SFCL and an energy storage device is suggested to improve the robustness of a micro-grid against short-circuit faults, and the results are able to show the effectiveness of the proposed approach.

For the application of non-superconducting FCLs in the micro-grid, a few preliminary studies have been done so far. In [25], a solid-state FCL based on the auto-triggered silicon control rectifier (SCR) is suggested for the micro-grid. In [26], a unidirectional FCL is used as the efficient interface between the micro-grid and the main network, and this unidirectional FCL is able to improve the coordinating performance of the overcurrent relays configured at the micro-grid. In [27], a multi-agent-based fault-current-limiting scheme for the micro-grid is presented, and the faulty section can be detected by the proposed fault-location approach and is segregated using the FCLs.

Actually, regardless of the concrete type of fault current limiter, the application of current-limiting technologies in the micro-grid has been proven to be meaningful, and herein, SFCL is selected as the main object for technical research. It should be noted that the employment of an SFCL in the micro-grid with intermittent renewable resources is very different from that of an SFCL in the main network, including large-scale synchronous generators. The conventional rotating electrical machines can provide a high fault current contribution with 5 to 15-times the rating level, but as the renewable resources are generally accessed in the grid through inverters, their fault current contributions will be restrained by power electronic equipment. Thus, it may not be recommended to excessively increase the current-limiting impedance of the SFCL used in the micro-grid.

In addition, the effects of introducing an SFCL will vary with its installation locations. There are three common installation locations for the SFCL used in the micro-grid, and they are respectively the point of common coupling (PCC) between the micro-grid and the main network, the critical transmission line and the integration point of DG units. Concerning the differences caused by SFCL locations, some brief explanations are provided as follows: (1) When the SFCL is installed at the PCC, it can be used to protect the entire micro-grid against the damage caused by an external fault, and the SFCL's promising effects can be approximately classified as two kinds in accordance with the severity (or specificity) of the external fault. One is to improve the micro-grid's FRT capability, and the other is to make the micro-grid carry out a smooth transition between its grid-connected and islanded modes when some permanent or serious faults occur; (2) Since the SFCL is installed at the transmission line with an important load, it is able to improve the service stabilities of the load; (3) If the SFCL is installed at the integration point of DG units, it can be used to improve the DG's FRT capability, in particular under the internal fault condition. It is well known that most of the DG units are connected to the micro-grid through inverters, and these inverter interfaced DGs (IIDGs) have highly variable characteristics and should meet the FRT requirements [28-31].

Considering the aforementioned individual differences related to the use of an SFCL, it is necessary to suggest an integrated technical evaluation method to assess the overall performance of one or more SFCLs. When these SFCLs' current-limiting impedances, access locations and installation quantities are changeable, their impacts on the micro-grid's power, voltage and frequency characteristics can be 
estimated. According to the comprehensive evaluation, the highly efficient transient enhancement of the micro-grid is beneficial to its future development.

In this paper, our research group focuses on the application of a flux-coupling-type SFCL into a typical micro-grid with photovoltaic (PV), wind generator and energy storage and proposes a suitable evaluation method to estimate the cases in which one or more SFCLs are installed. The article is organized in the following manner. Sections $2-4$ are devoted to present the SFCL's structural principle, discuss the fault characteristic of a typical micro-grid and propose the technical evaluation method where multiple performance indexes are taken into account. In Section 5, time-domain simulation is carried out in the MATLAB software, and different fault scenarios, as well as different SFCL configuration schemes are simulated to verify the evaluation method's effectiveness. In Section 6, relevant conclusions are summarized, and the next steps are suggested.

\section{Presentation of the Flux-Coupling-Type SFCL}

The main connection scheme of the flux-coupling-type SFCL is shown in Figure 1a [32]. This SFCL mainly consists of a coupling transformer $(\mathrm{CT})$, a controlled switch $\mathrm{S}_{\mathrm{cs}}$, a metal oxide arrester (MOA) $R_{\text {moa }}$ and a superconducting coil (SC). From the figure, $L_{1}, L_{2}$ are expressed as the CT's self-inductances; $M$ is the mutual inductance; $Z_{\mathrm{s}}$ is the circuit impedance; $\mathrm{S}_{\text {load }}$ is the circuit load; $R_{\mathrm{SC}} / R_{\text {moa }}$ is expressed as the SC/MOA's normal-state resistance. In accordance with the CT's equivalent circuit, which is composed of mutual-inductance and self-inductances, the SFCL's electrical equivalent structure is shown in Figure $1 b$.
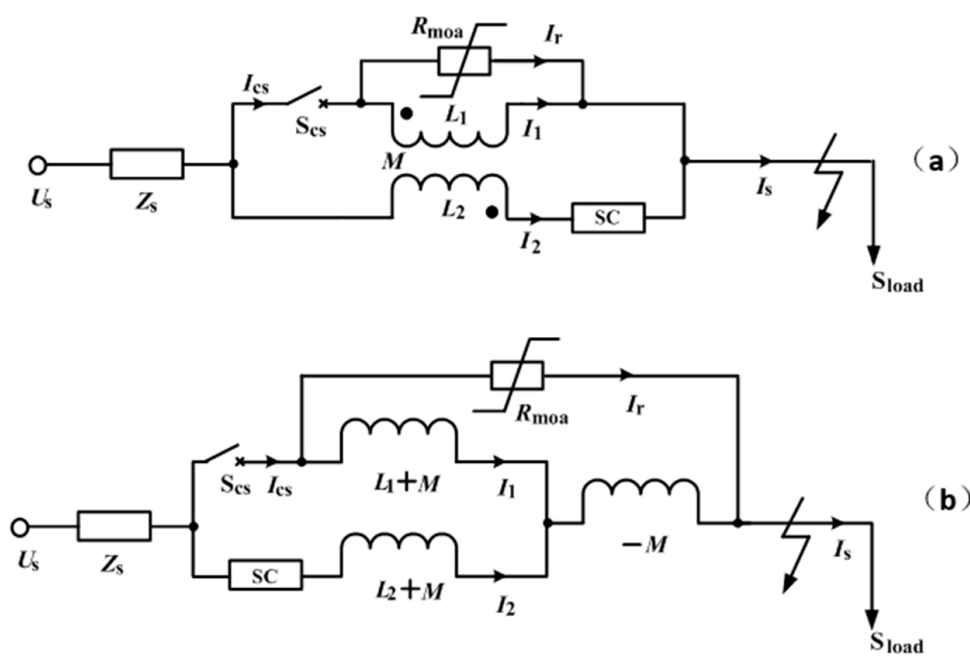

Figure 1. Flux-coupling-type SFCL. (a) Main connection and (b) electrical equivalent circuit.

In the normal condition, the switch $\mathrm{S}_{\mathrm{cs}}$ is closed, and the current flowing through the $\mathrm{SC}$ will be lower than its critical current. As the SC is maintained in the zero-resistance state and non-inductive coupling can be achieved [33], the MOA is "short-circuited", and the SFCL will not affect the main circuit.

In the case that a short-circuit fault happens, $S_{\mathrm{cs}}$ will be opened rapidly, and meanwhile, the MOA may suppress the overvoltage caused by the switching operation. Since the electromagnetic relationship is changed by the controlled switch, the non-inductive coupling will pass away, and also, the fault current in the SC will cause the superconductor to be quenched. The SFCL's current-limiting impedance can be calculated as: $Z_{\mathrm{SFCL}}=\left[R_{\mathrm{SC}}+j \omega L_{2}+\left(k n \omega L_{2}\right)^{2} /\left(R_{\text {moa }}+n^{2} \omega L_{2}\right)\right.$, where $n=\sqrt{L_{1} / L_{2}}$ and $k=M / \sqrt{L_{1} L_{2}}$. In view of $R_{\text {moa }} " n^{2} \omega L_{2}, Z_{\mathrm{SFCL}} \approx R_{\mathrm{SC}}+\mathrm{j} \omega L_{2}$ can be obtained.

Compared to the original flux-coupling-type SFCL, which is purely inductive [34-36], the suggested SFCL is a resistive-inductive-type (hybrid type) SFCL, which can potentially bring more positive contributions, such as inhibiting power fluctuations, restraining electromagnetic oscillations, as well as providing critical assistance to the reliabilities and securities of power systems more 
effectively [37]. The suggested SFCL equipped with the coupling transformer and the controlled switch has higher flexibility. Compared with the classical resistive-type SFCL being directly installed at the power system possibly having a longer recovery time, the current flowing through the suggested SFCL's superconducting coil can be adjusted by changing the transformation ratio, and meanwhile, the SFCL can be put into and out of operation with greater controllability of the switch. Furthermore, the use of the coupling transformer can reduce the AC loss of the superconducting coil and avoid the coil being directly impacted by the overcurrent at the initial time of the fault, which helps to promote the SFCL's engineering applications in different voltage grades of electric power networks. Compared to a classical inductive-type SFCL, the SFCL's resistive impedance can affect the generation units' active power characteristics more efficiently. Thus, the flux-coupling-type SFCL is suggested as the solution to improve the transient performance of the micro-grid system.

\section{Fault Characteristic Analysis of a Micro-Grid System with the Use of the SFCLs}

As shown in Figure 2, the configuration structure of a typical micro-grid system is indicated, which consists of a PV generation (DG1) unit, a wind generator (DG2), an energy storage device (DG3), as well as two power loads. R1, R2, . R9 denote the protective relays configured in the micro-grid, and they can be used to identify and remove the short-circuit faults. As a result, the relay protection function can be achieved. From this figure, all of the DG units are connected (or coupled) to the micro-grid through the inverters. No matter if the short-circuit fault occurs inside or outside the micro-grid, it is important to ensure the DG units' transient performance. In this section, the fault characteristics of the PV generation, wind generator, energy storage and power loads are respectively analyzed, and meanwhile, the SFCLs' positive effects are discussed in theory.

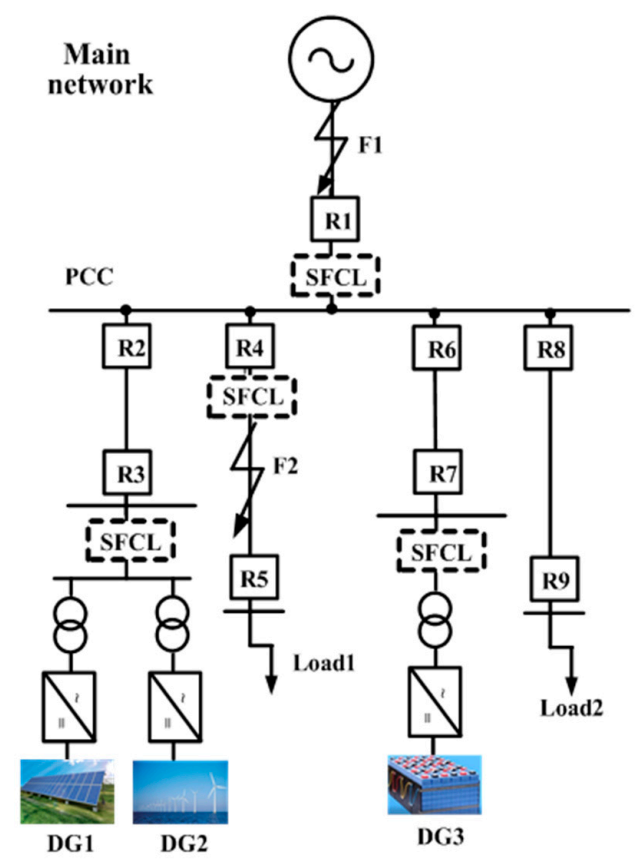

Figure 2. Schematic diagram of a typical micro-grid integrated with the SFCLs. PCC, point of common coupling.

\subsection{Fault Characteristic of the PV Generation}

Figure 3 indicates the configuration of a PV generation connected to the micro-grid, and herein, the maximum power point tracking (MPPT) control is used to ensure the PV system's operating efficiency. The transistors $\mathrm{V}_{\mathrm{T} 1} \ldots \mathrm{V}_{\mathrm{T} 6}$ denote the insulated gate bipolar transistors (IGBTs), and the 
pulse-width modulation (PWM) signals are used to drive the transistors. The overall power flowing through the PV generation can be defined by:

$$
P_{P V}=P_{D C 1}+P_{g}
$$

where $P_{D C 1}$ is the power flowing through the DC-link capacitor $C_{1} ; P_{g}$ is the power inserted by the inverter to the micro-grid; $P_{P V}$ is the PV array output. Supposing that the power electronic converter loss can be ignored under the normal condition, $P_{P V}$ is approximately equal to $P_{g}$, and it is obtained that $P_{P V}=P_{g}=3 U_{g} I_{g}$, where $U_{g}$ and $I_{g}$ are recorded as the nominal RMS value of phase voltage and phase current, respectively.

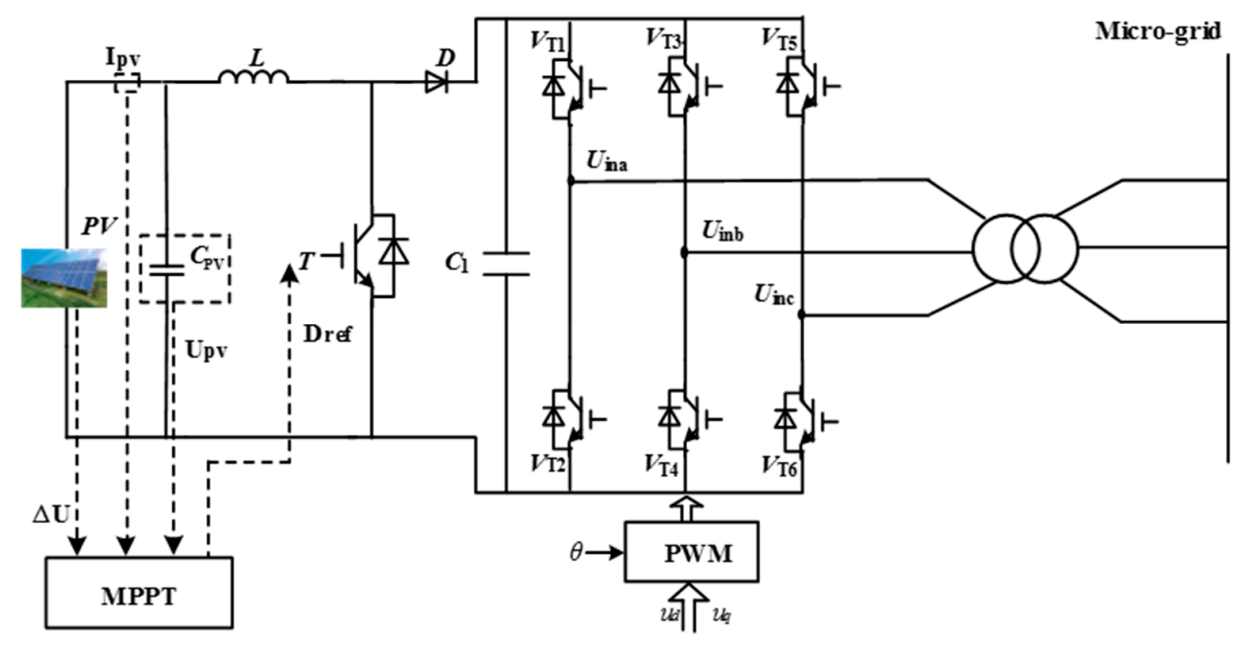

Figure 3. Schematic configuration of a grid-connected PV generation unit for the micro-grid. MPPT, maximum power point tracking.

When the short-circuit fault happens, the voltage over the PV generation unit will be dramatically affected, and the sudden voltage drop will reduce the grid-side power from $P_{g}$ to $P_{g f}$. Meanwhile, the DC/DC converter proceeds to transmit the PV array's maximum output power into the DC-link. Owing to the power imbalance between $P_{P V}$ and $P_{g f}$, the DC-link capacitance voltage will be forced to increase sharply [38], and it can be calculated as:

$$
V_{D C 1-f}=\sqrt{\frac{2\left(P_{P V}-3 U_{g f} I_{g f}\right) \Delta t}{C_{D C 1}}+V_{D C 1}^{2}}
$$

where $V_{D C 1}$ and $V_{D C 1-f}$ denote the DC-link capacitance voltage before and after the fault, and $\Delta t$ is expressed as the duration of the fault.

In response to the PV terminal-voltage sags, the inverter can adjust the reactive current for the voltage support. Thus, this section also suggests the control method of the inverter for the PV system. Regarding the voltage source inverter (VSI), which plays the role in the DC-AC power conversion for grid interfacing, it may use an external voltage regulator to generate the reference reactive current $I_{q p v-r e f}$, so as to keep a stable DC-link voltage, and herein, the reactive current's mathematical characteristic can be expressed as:

$$
\frac{I_{q}}{I_{n}}= \begin{cases}0 & \left(0.9 p u \leq V_{P V} \leq 1.1 p u\right) \\ a-a V_{P V} & \left(0.5 p u \leq V_{P V} \leq 0.9 p u\right) \\ 1 & \left(V_{P V}<0.5 p u\right)\end{cases}
$$

where the constant $a$ is set as two and $V_{P V}$ is the PV voltage; $I_{q}$ is the reactive current, and $I_{n}$ is the rated inverter current. In light of the required code, the VSI should provide full reactive current once the PV 
voltage is less than $50 \%$ of the nominal rating [39]. The reference reactive current under the fault can be determined by $I_{q p v-r e f}=I_{n}{ }^{*} I_{q} / I_{n}$, and then the active current reference $I_{d p v-r e f}$ can be expressed as:

$$
I_{d p v-r e f}= \begin{cases}I_{n} & \left(0.9 p u \leq V_{P V} \leq 1.1 p u\right) \\ \sqrt{I_{n}^{2}-I_{q p v-r e f}^{2}} & \left(0.5 p u \leq V_{P V} \leq 0.9 p u\right) \\ 0 & \left(V_{P V}<0.5 p u\right)\end{cases}
$$

In the case that the SFCL is installed at the integration point of the DG1 and the DG2, introducing the current-limiting impedance $\mathrm{Z}_{\mathrm{SFCL}}$ is able to compensate the voltage sags, so as to improve the PV generation's FRT capability. It should also be noted that using the SFCL can reduce the requirement for the injected reactive current of the VSI, and the SFCL's specific behaviors will be determined by the $\mathrm{CT}^{\prime} \mathrm{s}$ design parameters and the superconducting coil's rated capacity.

\subsection{Fault Characteristic of the Wind Generator}

As the variable-speed-type wind turbine adopting the doubly-fed induction generator (DFIG) has attracted more attention for wind generation, it is selected here to study and discuss the fault characteristics. Figure 4 shows the schematic diagram of a DFIG-based wind turbine connected to the micro-grid. From the equivalent park model of the DFIG, which is based on static stator-oriented reference frame [40], the following equations are obtained.

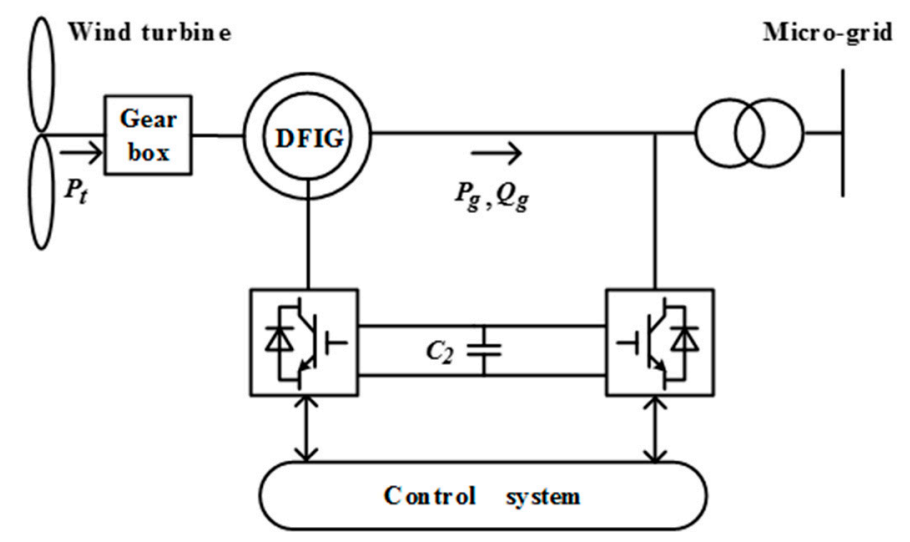

Figure 4. Schematic diagram of a doubly-fed induction generator (DFIG)-based wind turbine connected to the micro-grid.

$$
\begin{gathered}
\vec{V}_{s}=R_{s} \overrightarrow{i_{s}}+d \overrightarrow{\psi_{s}} / d t \\
\overrightarrow{\psi_{s}}=L_{s} \overrightarrow{i_{s}}+L_{m} \overrightarrow{i_{r}}
\end{gathered}
$$

where $\vec{V}, \vec{i}, \vec{\psi}, R, L$ are the voltage, current, magnetic flux, resistance and inductance, respectively. Subscripts $s, r, m$ denote the stator, rotor and mutual quantities, respectively. Assuming that the DFIG's terminal voltage will drop from $V_{s 1}$ to $V_{s 2}$ under the fault ( $t_{0}$ is the fault occurrence time), it can be defined by:

$$
\vec{V}_{s}= \begin{cases}V_{s 1} e^{\mathrm{j} \omega_{s} t} & t<t_{0} \\ V_{s 2} e^{\mathrm{j} \omega_{s} t} & t \geq t_{0}\end{cases}
$$

Supposing that the rotor current is controlled and the rotor-side converter keeps on working, the rotor current is approximately constant. Its expression transferred to the stator-side is:

$$
\overrightarrow{i_{r}}=I_{r} e^{\mathrm{j}\left(\omega_{r}+\omega\right) t}=I_{r} e^{\mathrm{j} \omega_{s} t}
$$


According to constant-linkage theorem [41], the DFIG's stator flux before and after the fault will be expressed as:

$$
\overrightarrow{\psi_{s}}= \begin{cases}\frac{V_{s 1} L_{s}}{R_{s}+\mathrm{j} \omega_{s} L_{s}} e^{\mathrm{j} \omega_{s} t}+\frac{R_{s} L_{s} I_{r}}{R_{s}+\mathrm{j} \omega_{s} L_{s}} e^{\mathrm{j} \omega_{s} t} & t<t_{0} \\ \frac{V_{s 2} L_{s}}{R_{s}+\mathrm{j} \omega_{s} L_{s}} e^{\mathrm{j} \omega_{s} t}+\frac{R_{s} L_{s} I_{r}}{R_{s}+\mathrm{j} \omega_{s} L_{s}} e^{\mathrm{j} \omega_{s} t}+\vec{\psi}_{0} e^{-\frac{R_{s}}{L_{s}} t} & t \geq t_{0}\end{cases}
$$

where $\overrightarrow{\psi_{0}}=L_{s}\left(V_{s 1}-V_{s 2}\right) e^{\mathrm{j} \omega_{s} t_{0}} /\left(R_{s}+\mathrm{j} \omega_{s} L_{s}\right)$, and it denotes the stator flux's natural component. By neglecting the stator resistance in Equation (9), the stator flux can be rewritten as:

$$
\overrightarrow{\psi_{s}}= \begin{cases}\frac{V_{s 1}}{\mathrm{j} \omega_{s}} e^{\mathrm{j} \omega_{s} t} & t<t_{0} \\ \frac{V_{s 2}}{\mathrm{j} \omega_{s}} e^{\mathrm{j} \omega_{s} t}+\frac{\left(V_{s 1}-V_{s 2}\right) e^{\mathrm{j} \omega_{s} t_{0}}}{\mathrm{j} \omega_{s}} e^{-\frac{R_{s}}{L_{s}} t} & t \geq t_{0}\end{cases}
$$

The stator current can be deduced by:

$$
\overrightarrow{i_{s}}=\frac{\overrightarrow{\psi_{s}}-L_{m} \overrightarrow{i_{r}}}{L_{s}}
$$

In the case of combining with Equations (10) and (11), the AC fault current across the DFIG's stator winding can be calculated in:

$$
\overrightarrow{i_{s}}=\frac{\left(V_{s 1}-V_{s 2}\right) e^{\mathrm{j} \omega_{s} t_{0}}}{\mathrm{j} \omega_{s} L_{s}} e^{-\frac{R_{s}}{L_{s}} t}+\frac{V_{s 2}}{\mathrm{j} \omega_{s} L_{s}} e^{\mathrm{j} \omega_{s} t}-\frac{L_{m} \overrightarrow{i_{r}}}{L_{s}}
$$

Since the flux-coupling-type SFCL is applied at the integration point of the DG1 and DG2, the contribution of introducing the current-limiting impedance is to compensate the generator terminal-voltage sag and improve $L_{s}$. From Equation (12), the AC fault current flowing through the DFIG's stator side can be suppressed.

\subsection{Fault Characteristic of the Energy Storage}

Herein, battery energy storage (DG3) is adopted to carry out the theoretical analysis, and its fault characteristic is analyzed in brief. Commonly, the battery energy storage will switch to the voltage-frequency (V-F) control from the original active power-reactive power (P-Q) control, when the micro-grid is undergoing a serious fault, and will switch to the islanded mode. According to the general V-F control block diagram shown in Figure 5 [42], an inductor-capacitor (LC) filter is adopted, and the capacitor voltage is measured for feedback control. The control equation can be expressed as:

$$
P_{m}=\left(k_{p}+k_{s} / s\right)\left(U_{r e f}-U_{B E}\right)
$$

where $P_{m}$ is the power modulation factor; $k_{p}$ and $k_{s}$ are respectively the controller's proportional coefficient and integral coefficient, and the proportional-integral (PI) controller is denoted in Figure 5; $U_{r e f}$ is the reference voltage; $U_{B E}$ is the battery energy storage's output voltage, which is coupled to the micro-grid. If the factor $P_{m}$ is not beyond the threshold value (set as one) during the process of the fault, $U_{B E}$ can be quickly and effectively adjusted. In this situation, the battery energy storage can be equivalent to a constant voltage source, and $U_{B E}=U_{r e f}$ is achieved. If $P_{m}$ is more than the threshold value, the amplitude-limiting function will be activated by the converter to make $P_{m}=1$, and the following voltage equation can be obtained.

$$
\dot{U_{B E}}=\dot{E_{B E}}-\dot{I_{B E}} Z_{f}
$$

where $E_{B E}$ is the output voltage of the energy storage converter; $Z_{f}$ is the equivalent impedance. 


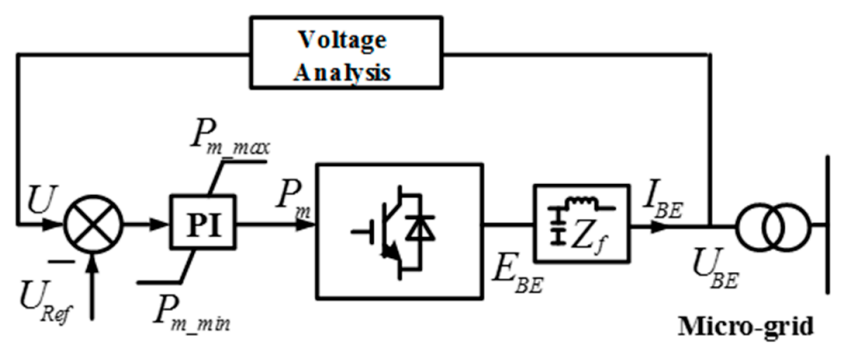

Figure 5. General voltage-frequency (V-F) control block diagram for the energy storage connected to the micro-grid.

From Equation (14), introducing the SFCL will have no influence on the battery storage's output voltage in the case of $P_{m}<1$. When $P_{m}=1$, the voltage equation can be rewritten as:

$$
\dot{U_{B E}}=\dot{E_{B E}}-\dot{I_{B E}}\left(Z_{f}+Z_{S F C L}^{\prime}\right)
$$

where $Z_{S F C L}^{\prime}$ is the SFCL's equivalent current-limiting impedance, which is converted from the set-up transformer's high-voltage side to the low-voltage side.

Owing to the introduction of the flux-coupling-type SFCL, it has a natural function of limiting the fault current, and during the process of current limitation, its impedance is actually connected in series with the main circuit. Considering that the SFCL is installed near the set-up transformer with the energy storage unit, it can be obtained that introducing the current-limiting impedance causes the energy storage unit to be far away from the fault location. Thus, although the voltage sag at the fault location cannot be avoided, the energy storage unit's output voltage can be improved as compared with the case without the SFCL.

\subsection{Fault Characteristic of the Power Loads}

Virtually all loads included in the micro-grid system can be simulated by linear resistor-inductor (RL) branches. Roughly $60 \%$ of the electrical loads in distribution networks are composed of direct-connected induction motor (IM) loads [43]. In this paper, one of the two loads in the micro-grid (Load 2) is regarded as the IM load, and the fault analysis is performed in brief.

For demonstration purposes, a simple mathematical representation based on a first-order IM model is presented, and the IM rotational speed $\omega_{\text {fault }}$ during the fault can be expressed as [44]:

$$
\omega_{\text {fault }}=\frac{n_{1}}{m_{1}}+\left(\omega_{\text {nom }}-\frac{n_{1}}{m_{1}}\right) e^{-a_{1}\left(t-t_{1}\right)}
$$

where $m_{1}=\frac{K_{p} V_{p, f a u l t}^{2}+K_{n} V_{n, f a u l t}^{2}}{J \omega_{s-I M}}, \quad n_{1}=\frac{K_{p} V_{p, f a u l t}^{2}-K_{n} V_{n, f a u l t}^{2}-T_{L}}{J}, \quad K_{p}=\frac{3}{\omega_{s-I M} R_{r-I M}^{\prime}}$, $K_{n}=\frac{3 R_{r-I M}^{\prime}}{\omega_{s-I M}\left[\left(2 R_{s-I M}+R_{r-I M}^{\prime}\right)^{2}+4\left(X_{s-I M}+X_{r-I M}^{\prime}\right)^{2}\right]}$. Herein, $T_{L}$ is the mechanical load torque; $J$ is the moment of inertia; $\omega_{s-I M}$ is the synchronous speed; and $\omega_{\text {nom }}$ is the pre-fault speed of the IM. The parameters $R_{r-I M}^{\prime}, X_{r-I M}^{\prime}, R_{S-I M}, X_{S-I M}$ represent the rotor resistance, rotor reactance, stator resistance and stator reactance, respectively.

From Equation (16), the IM speed reduces exponentially with the time, and the corresponding time constant is $1 / m_{1}$. If the fault clearance time is more than $1 / m_{1}$, the rotational speed might settle at another stable rotational speed provided that the mechanical load torque is lower than the maximum torque given from the IM torque-speed characteristics in the fault condition. IM stalling or unstable micro-grid operation is most likely to occur for higher mechanical load torques and/or severe voltage dip levels.

Considering that the flux-coupling-type SFCL is installed at the transmission line with Load 1, it can help to improve the PCC voltage under the fault, compared to the PCC voltage approximately 
dropping to zero in the case of a serious short-circuit fault. In a sense, the improvement of the PCC voltage can enhance the service stability of the IM load, and the requirement for the shorter fault clearance time can be properly reduced.

\section{Technical Evaluation of the SFCLs Used in a Micro-Grid by Considering Multiple Indexes}

In consideration of the above-mentioned individual differences related to the use of a SFCL, this section investigates an integrated technical evaluation method to assess the overall performance of one or more SFCLs used in the micro-grid. Since the current and voltage of a micro-grid or a DG unit are the most intuitive in nature (the power and frequency characteristics can be theoretically analyzed by the current and voltage), the impacts of an SFCL on them cannot be ignored. In addition, since the SFCL is used in a micro-grid whose entire capacity is relatively smaller than a large-scale main network, it is meaningful and valuable to investigate its economics and possible effects on the generation cost. In sum, three crucial performance indexes, including current-limiting performance, bus voltage stability and device cost, are taken into account.

\subsection{Evaluation of Current-Limiting Performance}

In regard to the behaviors of an SFCL, its current-limiting performance is a key evaluation indicator with certainty. Herein, it is the first evaluation sub-function being described as:

$$
J_{1}=\sum_{c=1}^{n}\left|\frac{I_{\text {without }-S F C L}^{c}}{I_{\text {without-SFCL }}^{c}-I_{\text {with }-S F C L}^{c}}\right|
$$

where $I_{\text {without-SFCL }}^{c}$ and $I_{\text {with-SFCL }}^{c}$ respectively indicate the short-circuit current at grid-bus (or DG bus) $c$ in the case of without and with the SFCLs. In particular, the short-circuit current in the transmission line connecting with the micro-grid and the main network may be also pointedly calculated.

\subsection{Evaluation of Voltage Stability}

Concerning the second evaluation sub-function, it is used to assess the SFCLs' influence on the bus or DG voltage stability, and this sub-function is defined by:

$$
J_{2}=\sum_{c=1}^{n}\left|\frac{V_{\text {normal-state }}^{c}}{V_{\text {without }-S F C L-f}^{c}-V_{\text {with }-S F C L-f}^{c}}\right|
$$

where $V_{\text {without }-S F C L-f}^{c}$ and $V_{\text {with-SFCL-f }}^{c}$ respectively denote the bus voltage (or the DG voltage) $c$ under the fault in the case of without and with the SFCLs; $V_{\text {normal-state }}^{c}$ is recorded as the bus voltage (or the DG voltage) $c$ under the normal condition.

\subsection{Evaluation of Device Cost}

In consideration of the SFCL cost, it has close relations with the current-limiting impedances and the installation number of the SFCLs, and it can be expressed as [45]:

$$
C_{S F C L}=\sum_{i=1}^{N_{S F C L}} Z_{S F C L}(i)+d N_{S F C L}+F_{a}
$$

where $Z_{S F C L}(i)$ is the current-limiting impedance of the $i$-th SFCL; $N_{S F C L}$ is the installation number; $d$ is the cost coefficient; $F_{a}$ is a penalty function.

The DG units' generation cost can be calculated by [46]:

$$
C_{D G}=\sum_{i=1}^{N_{D G}} P_{D G-i}\left\{\left[\frac{r_{i}\left(1+r_{i}\right)^{n_{\mathrm{p}}}}{\left(1+r_{i}\right)^{n}-1}\right]\left(\frac{C_{a z-i}}{8760 c_{i}}\right)+C_{O M-i}\right\}
$$


where $P_{D G-i}$ is the generation power of the $i$-th DG; $c_{i}$ is the capacity coefficient; $n_{p}$ is the pay-back period; $N_{D G}$ is the number of the DG units; $C_{a z-i}$ and $C_{O M-i}$ are the investment cost and maintenance cost, respectively.

The cost of the energy storage device (taking the battery storage for the research object) can be calculated by:

$$
C_{E S}=C_{P} P_{\max }+C_{E} E_{E S}+C_{O M-E S}
$$

where $P_{\max }$ is the maximum power of the energy storage; $E_{E S}$ is the rated storage energy; $C_{O M-E S}$ is the maintenance cost; $C_{p}$ and $C_{E}$ are marked as the equivalent coefficients.

Accordingly, the third evaluation sub-function related to the cost analysis is defined by:

$$
J_{3}=\frac{\sum_{i=1}^{N_{S F C L}} Z_{S F C L}(i)+d N_{S F C L}+F_{a}}{\sum_{i=1}^{N_{D G}} P_{D G-i}\left\{\left[\frac{r_{i}\left(1+r_{i}\right)^{n}}{\left(1+r_{i}\right)^{n}-1}\right]\left(\frac{C_{a z-i}}{8760 c_{i}}\right)+C_{O M-i}\right\}+C_{P} P_{\max }+C_{E} E_{E S}+C_{O M-E S}}
$$

In the case of combining with the aforementioned three sub-functions, the integrated technical evaluation function can be expressed as:

$$
J_{\text {int-eva }}=w_{1} J_{1}+w_{2} J_{2}+w_{3} J_{3}
$$

where $w_{1}, w_{2}, w_{3}$ are the weightings assigned to the sub-functions, which are to assess the decrease of the fault current, the inhibition of the voltage fluctuation and the SFCL/DG/storage cost, respectively. In a sense, the setting of the weightings should be crucial and would eventually be fixed by conditions and experiences for the characteristics of a given system. During the following simulation analyses, different configuration schemes for the weightings are taken into account.

\section{Simulation Studies and Verification}

\subsection{Modeling and Parameters}

In this section, for the sake of assessing the performance of the SFCLs and the effectiveness of the evaluation method, a detailed simulation model corresponding to Figure 2 is built in MATLAB/Simulink, and parts of the simulation parameters are indicated in Table 1.

Table 1. Main simulation parameters of the demonstrated system.

\begin{tabular}{cc}
\hline \multicolumn{2}{c}{ Demonstrated Micro-Grid System } \\
\hline DG1/DG2/DG3 & $180 \mathrm{~kW} / 100 \mathrm{~kW} / 150 \mathrm{~kW}$ \\
Transmission Line & $0.27+\mathrm{j} 0.347 \Omega / \mathrm{km}, 2 \mathrm{~km}$ \\
Load 1/Load 2 & $350 \mathrm{~kW} / 250 \mathrm{~kW}$ \\
PCC Voltage/Frequency & $10 \mathrm{kV} / 50 \mathrm{~Hz}$ \\
\hline \multicolumn{2}{c}{ Flux-Coupling-Type SFCL } \\
\hline Primary Inductance & $50 \mathrm{mH} / 70 \mathrm{mH} / 90 \mathrm{mH}$ \\
Coupling Coefficient/Coil Ratio & $0.99 / 0.5$ \\
Superconducting Coil $R_{\mathrm{SC}}$ & $10 \Omega / 30 \Omega / 50 \Omega$ \\
\hline
\end{tabular}

Note that the DG1 and DG2 will always adopt the P-Q control, and the DG3 will switch to the V-F control from the original P-Q control when the micro-grid should be separated from the main network. Figure 6 shows the schematic diagram of the control mode switching of the DG3. From the figure, the control switching should consider the SFCL's action signal and the fault location result, which will be sent to the control system of DG3 for operating the two logical switches. 


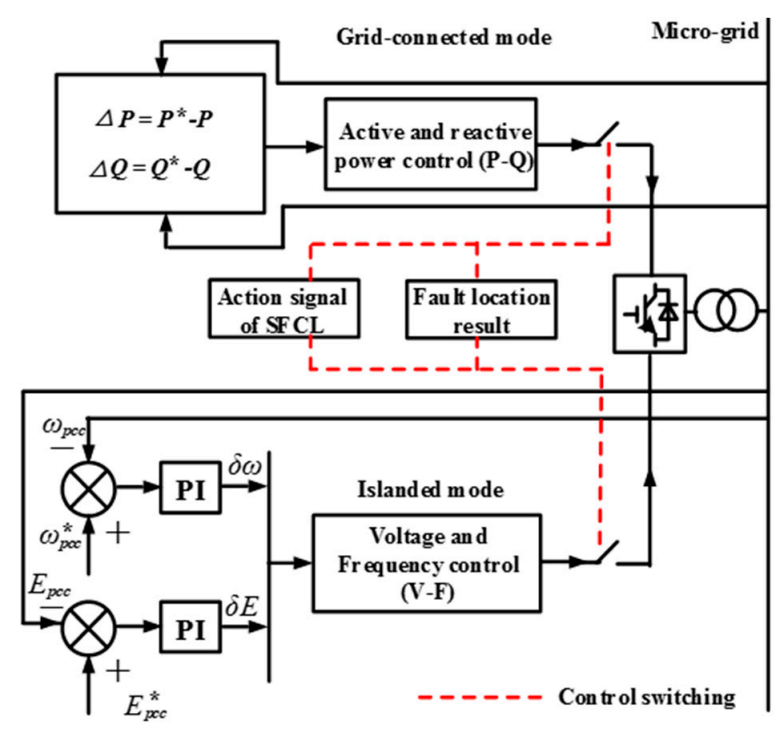

Figure 6. Control mode switching of the battery energy storage (DG3).

During the simulation, the SFCL's controlled switch is simulated by an anti-parallel IGBT pairs, and the coupling transformer is based on a standard transformer model from the MATLAB model library. The quench/recovery model of the superconducting coil is according to Figure 7 [47], and the $\mathrm{SC}^{\prime}$ 's operating characteristic can be expressed as:

$$
R(t)= \begin{cases}0 & \left(t<t_{0}\right) \\ R_{n}\left[1-\exp \left(-\frac{t-t_{0}}{\tau}\right)\right]^{1 / 2} & \left(t_{0} \leq t<t_{1}\right) \\ a_{1}\left(t-t_{1}\right)+b_{1} & \left(t_{1} \leq t<t_{2}\right) \\ a_{2}\left(t-t_{2}\right)+b_{2} & \left(t_{2} \leq t\right)\end{cases}
$$

where $R_{n}$ denotes the SFCL's normal-state resistance; $\tau$ is the time constant. The SFCL's time-domain characteristic is stated such that $t_{0}, t_{1}$ and $t_{2}$ indicate the quench-starting time, the first recovery-starting time and the secondary recovery-starting time, respectively. $a_{1}, b_{1}, a_{2}$ and $b_{2}$ are respectively the function coefficients. It is assumed that the SC will enter the quenching state within $4 \mathrm{~ms}$, and after the short-circuit fault is removed, the $\mathrm{SC}^{\prime} \mathrm{s}$ recovery time is set as $0.5 \mathrm{~s}$ to cooperate with the reclosing.

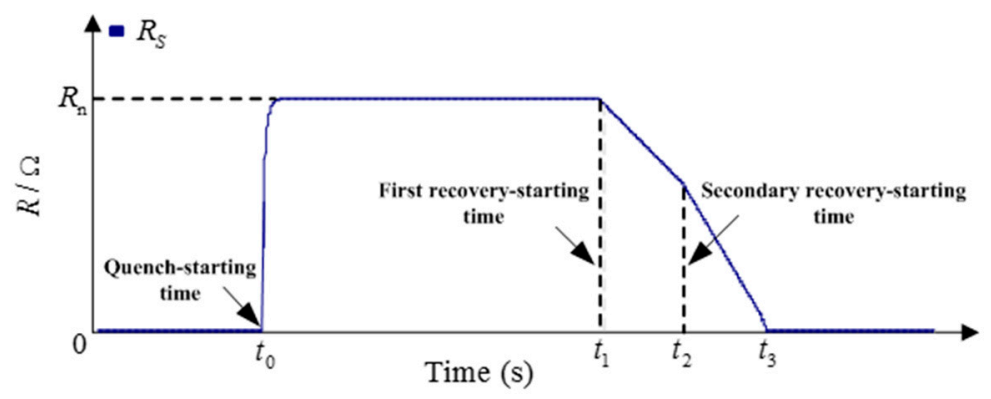

Figure 7. Quench/recovery of the superconducting coil used in the SFCL.

As shown in Figure 8, different FRT curves of a defined stay-connected time for IIDG are indicated $[48,49]$. From this figure, the FRT requirement differs from one standard to the other based on the countries' grid code. During the simulations, the Denmark code is selectively used, and in the case that the grid voltage drops to $20 \%$ of the nominal level, the IIDG should remain in the grid-connected state for a duration of $150 \mathrm{~ms}$. 


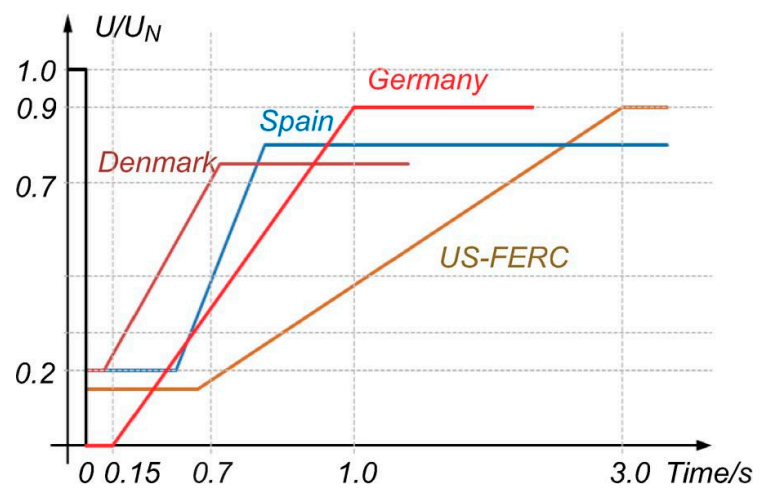

Figure 8. Different fault ride through (FRT) curves of a defined stay-connected time for the inverter interfaced DG (IIDG).

In addition, based on the consideration of a simplified analysis, the DG1, DG2 and DG3 are physically connected to the same inverter bus during the simulations, and accordingly, the installation number of the SFCLs can be appropriately reduced. In the following analyses, the external fault (F1 point) and the internal fault (F2 point) are both simulated, and the computed results of the evaluation function are also given.

\subsection{Simulations of the External Fault (F1 Point)}

In the normal (no fault) condition, the energy storage device's effects on eliminating the power fluctuations caused by the intermittent energy sources are taken into account, and the DGs' overall active power will be controlled as $300 \mathrm{~kW}\left(P_{\mathrm{DG} 1}+P_{\mathrm{DG} 2}+P_{\mathrm{DG} 3}=300 \mathrm{~kW}\right)$. In other words, the micro-grid's power shortage with the capacity value of $300 \mathrm{~kW}$ will be supported by the main network. Furthermore, the simulation conditions of the external fault (F1 point) are described as a three-phase ground fault happening at $t=1 \mathrm{~s}$; the fault resistance is $1 \Omega$; the duration of the fault is $0.2 \mathrm{~s}$. In regard to this fault case, only one SFCL is installed at the PCC, and it is expected to protect the entire micro-grid system from the fault damage.

Different SFCL parameters are also considered, and Figure 9 shows the fault current flowing from the micro-grid side to the PCC (taking the A-phase as an example). The SFCL's current-limiting effects will become more obvious along with the increase of the SFCL parameters, but since the fault current is mainly contributed by the DG units, the maximum amplitude of the fault current will generally not reach a very high level. From this perspective, it may not be necessary to excessively increase the SFCL parameters.

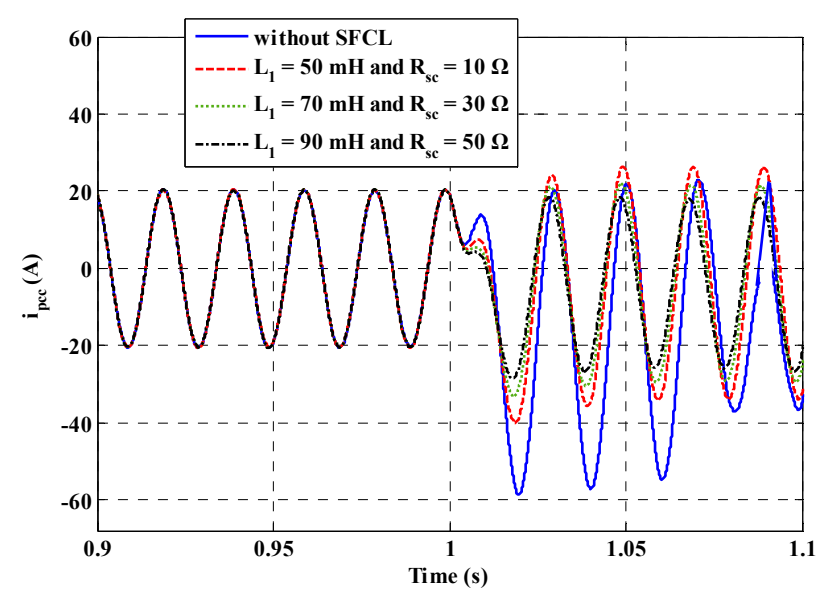

Figure 9. Fault current from the micro-grid side to the PCC under the external fault (A-phase). 
Figure 10 shows the micro-grid's PCC voltage under the external fault (A-phase). From this figure, the PCC voltage will be down to $53 \%$ of the nominal level in the case of without SFCL. Once the flux-coupling-type SFCL is employed, the PCC voltage can be even improved to $82 \%$ of the nominal level, and it is conducive to enhance the FRT capabilities of the IIDG units. Figures 11-13 show the exchange power and frequency response of the micro-grid system under the external fault. Before the micro-grid is forced to be disconnected from the main network at $t=1.13 \mathrm{~s}$, the voltage drop at the PCC will greatly affect the power exchange.

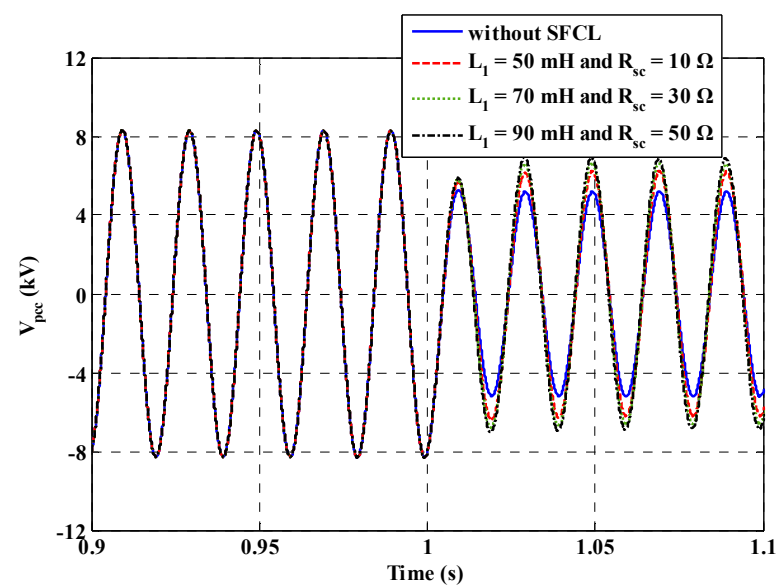

Figure 10. PCC voltage characteristic of the micro-grid system under the external fault (A-phase).

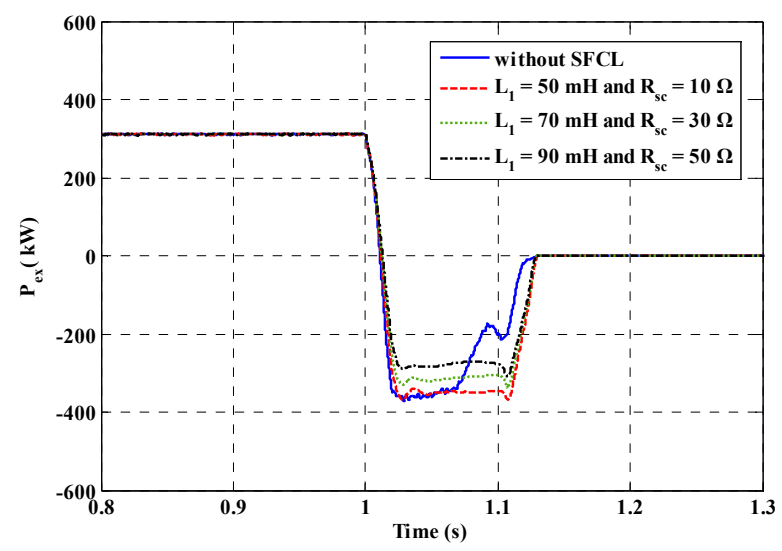

Figure 11. Active power of the micro-grid at the PCC under the external fault.

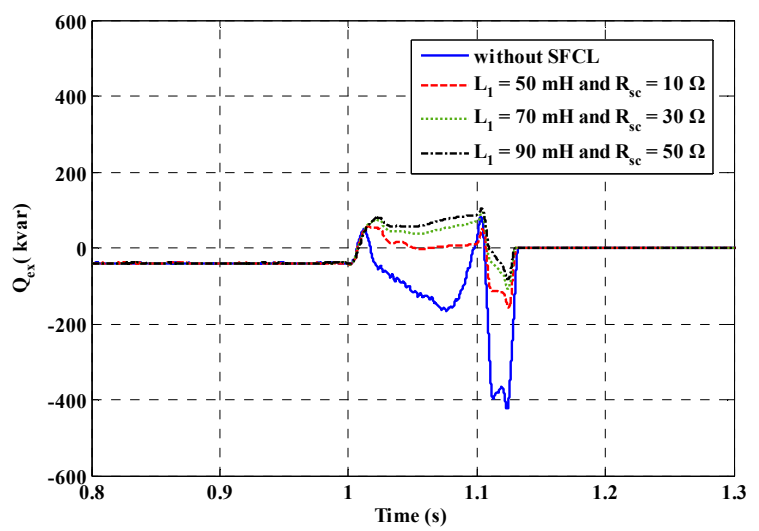

Figure 12. Reactive power of the micro-grid at the PCC under the external fault. 


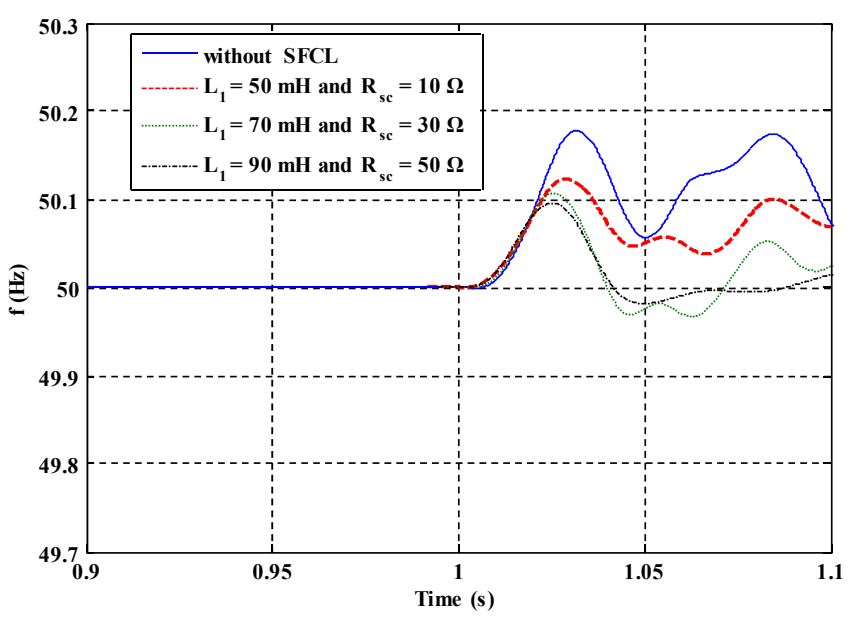

Figure 13. Frequency fluctuations of the micro-grid under the external fault.

Regarding the setting of the disconnection time, a brief explanation is given. When the external fault occurs, the disconnection time of the micro-grid will closely depend on the relay protection's algorithm strategy and the PCC switch's response speed. In this paper, according to a general protection configuration method used in the power distribution network, the directional overcurrent protection can be appreciatively used in the micro-grid, and once the fault current flowing through the PCC meets the setting conditions, the relay protection (R1) will trip off the PCC switch to separate the micro-grid under the external fault. For R2-R9, they can be used to deal with the internal fault. From the literature [50-52], the whole action time of the directional overcurrent protection can be reduced to 6-7 fundamental-frequency cycles in the case that the protection parameters are properly set. Therefore, the disconnection is supposed to be effective at $t=1.13 \mathrm{~s}$, and namely, the islanded mode will be activated at $130 \mathrm{~ms}$ after the fault.

After the fault occurs, the exchange power's flowing direction will be reversed, and the micro-grid will transmit power energy to the main network. Owing to the use of the SFCL, the fluctuating margin of the exchange power can be reduced to a certain extent. Moreover, the micro-grid frequency's fluctuating margin is about $0.18 \mathrm{~Hz}$ in the case of without SFCL, and it may be suppressed within the level of $0.09 \mathrm{~Hz}$ when the SFCL is employed.

According to the simulation results, each of the three evaluation sub-functions will be calculated, and herein, some of the calculation parameters are listed: the commercial superconducting tapes have a high resistivity matrix with a linear resistance of $0.354 \Omega / \mathrm{m}$, and the tape cost is $70 \$ / \mathrm{m}$; the generating costs of the wind power and the photovoltaic DG are respectively set as $1283.697 \$ / \mathrm{kW}$ and $2384.8514 \$ / \mathrm{kW}$ [53]; in regard to the cost of the energy storage device, $C_{\mathrm{p}}=426 \$ / \mathrm{kW}$, $C_{\mathrm{E}}=180 \$ / \mathrm{Ah}$ and $C_{\mathrm{om}-\mathrm{ES}}=13.5 \$ / \mathrm{kW}$ [54]. Herein, the battery cost parameters are suitable for the vanadium redox flow battery (VRFB), and its rated voltage is set as $800 \mathrm{~V}$. In accordance with those different current-limiting parameters of the SFCL, the calculation results of the three evaluation sub-functions are shown in Table 2.

Table 2. Calculation results of the three evaluation sub-functions under different current-limiting parameters (external fault).

\begin{tabular}{cccc}
\hline \multirow{2}{*}{ Current-Limiting Parameters } & \multicolumn{3}{c}{ Evaluation Sub-Functions } \\
\cline { 2 - 4 } & $\boldsymbol{J}_{\mathbf{1}}$ & $\boldsymbol{J}_{\mathbf{2}}$ & $\boldsymbol{J}_{\mathbf{3}}$ \\
\hline$L_{1}=50 \mathrm{mH}$ and $R_{\mathrm{SC}}=10 \Omega$ & 20.9013 & 25.4615 & 5.5087 \\
$L_{1}=70 \mathrm{mH}$ and $R_{\mathrm{SC}}=30 \Omega$ & 17.2433 & 18.6047 & 10.504 \\
$L_{1}=90 \mathrm{mH}$ and $R_{\mathrm{sc}}=50 \Omega$ & 14.6096 & 16.0384 & 14.8169 \\
\hline
\end{tabular}


For the calculation of the integrated technical evaluation function $\left(J_{\text {int-eva }}\right)$, the setting of the weightings $w_{1}, w_{2}, w_{3}$ will be critical, and herein, four typical allocation schemes are taken into account. The detailed calculation results are shown in Table 3. The change of the weightings will closely determine the final numerical value of the evaluation function. In addition, along with the augment of the SFCL's current-limiting parameters, the function value will decrease at first then increase under the condition of $w_{1}=0.3, w_{2}=0.3, w_{3}=0.4$. When the function value is smaller, the SFCL's comprehensive performance behaviors will be better. It may be inferred that there will be a compromise design for the SFCL parameters to fully obtain the performance advantages.

Table 3. Calculation results of the integrated technical evaluation function under different weighting factors (external fault).

\begin{tabular}{ccccc}
\hline & \multicolumn{3}{c}{ Integrated Technical Evaluation Function $\left(J_{\text {int-eva }}\right)$} \\
\cline { 2 - 5 } Current-Limiting & $\boldsymbol{w}_{\mathbf{1}}=\mathbf{0 . 1}$, & $\boldsymbol{w}_{\mathbf{1}}=\mathbf{0 . 1}$, & $\boldsymbol{w}_{\mathbf{1}}=\mathbf{0 . 8}$, & $\boldsymbol{w}_{\mathbf{1}}=\mathbf{0 . 3}$, \\
Parameters & $\boldsymbol{w}_{\mathbf{2}}=\mathbf{0 . 1}$, & $\boldsymbol{w}_{\mathbf{2}}=\mathbf{0 . 8}$, & $\boldsymbol{w}_{\mathbf{2}}=\mathbf{0 . 1}$, & $\boldsymbol{w}_{\mathbf{2}}=\mathbf{0 . 3}$, \\
& $\boldsymbol{w}_{\mathbf{3}}=\mathbf{0 . 8}$ & $\boldsymbol{w}_{\mathbf{3}}=\mathbf{0 . 1}$ & $\boldsymbol{w}_{\mathbf{3}}=\mathbf{0 . 1}$ & $\boldsymbol{w}_{\mathbf{3}}=\mathbf{0 . 4}$ \\
\hline$L_{1}=50 \mathrm{mH}$ and $R_{\mathrm{sc}}=10 \Omega$ & 9.0432 & 23.0102 & 19.8181 & 16.1123 \\
$L_{1}=70 \mathrm{mH}$ and $R_{\mathrm{sc}}=30 \Omega$ & 11.9882 & 17.6585 & 16.7055 & 14.9561 \\
$L_{1}=90 \mathrm{mH}$ and $R_{\mathrm{sc}}=50 \Omega$ & 14.9183 & 15.7734 & 14.7732 & 15.1212 \\
\hline
\end{tabular}

Noted that this conclusion will be effective when the three weightings have similar values or have a little difference, and in general, it may not be recommended to excessively emphasize a certain weighting since the other weightings will lose their importance and significance [55]. In addition, if the proposed technical evaluation function is used to optimally select and place the SFCLs in the micro-grid, the optimization objective is to make the integrated function value be the smallest, and the SFCLs' current-limiting impedances, access locations and installation quantities will be constrained by certain conditions. Due to the use of an intelligent algorithm, such as particle swarm optimization (PSO) [56,57], the optimization results can be selectively obtained. As this paper's main objective is to do the technical evaluation and provide a quantitative comparison, the detailed optimization works will be performed and reported in later articles.

\subsection{Simulations of the Internal Fault (F2 Point)}

When the internal fault happens at the F2 point, it is expected to improve the micro-grid's FRT capability. Under this fault, the micro-grid system does not have to disconnect from the main network, in particular when the power exchange is considerable. During the transient simulations, two SFCLs are employed. One of them is installed at the integration point of the DG units, and the other is installed at the PCC. The two SFCLs are respectively used to limit the fault contributions from the DG units and the main network, and their parameters are supposed to be the same as each other.

For the internal fault, the fault occurrence time is $t=1 \mathrm{~s}$; the fault resistance is $1 \Omega$; the duration of the fault is $0.2 \mathrm{~s}$. Figures 14 and 15 show the waveforms of the fault currents contributed by the DG units and the main network, respectively. From the figures, using the SFCLs, one is able to limit the fault currents within acceptable levels. Herein, the fault current in the PCC is selected for data analysis. The fault current's peak value will rise to $740 \mathrm{~A}$ without the SFCL. Since the SFCL parameters are respectively set as $L_{1}=50 \mathrm{mH}$ and $R_{\mathrm{sc}}=10 \Omega, L_{1}=70 \mathrm{mH}$ and $R_{\mathrm{sc}}=30 \Omega, L_{1}=90 \mathrm{mH}$ and $R_{\mathrm{sc}}=50 \Omega$, the fault current's peak value can be respectively suppressed to $180 \mathrm{~A}, 117 \mathrm{~A}, 89 \mathrm{~A}$, and the current-limiting ratio is about $75.7 \%, 84.2 \%, 88 \%$. 


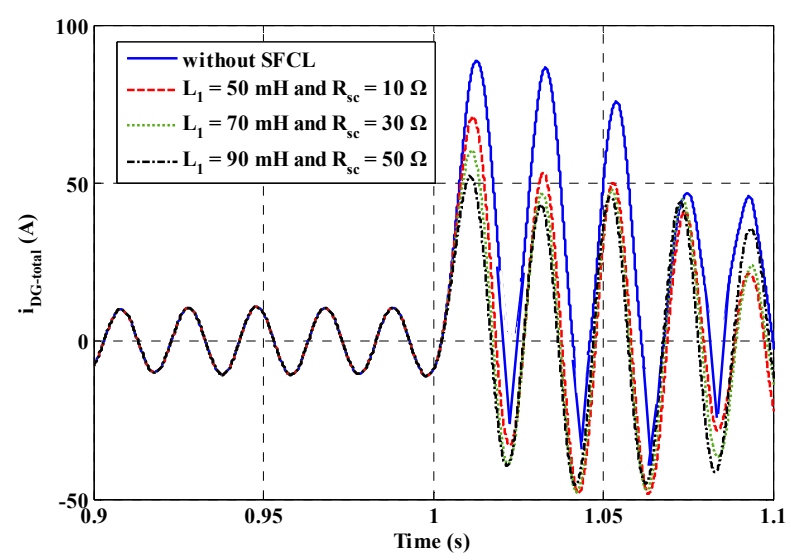

Figure 14. Fault current contributed by the DG units under the internal fault (A-phase).

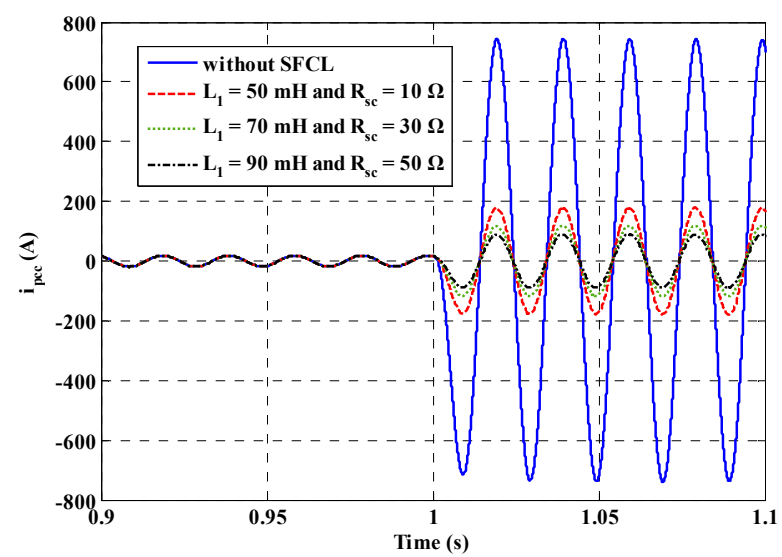

Figure 15. Fault current provided by the main network under the internal fault (A-phase).

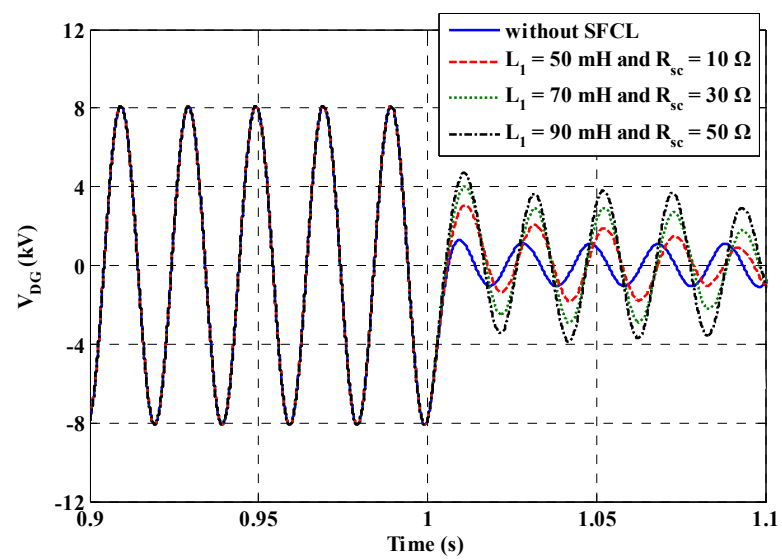

Figure 16. Voltage at the integration point of the DG units under the internal fault (A-phase).

Figures 16-19 show the DG voltage, exchange power and frequency fluctuations of the micro-grid system under the internal fault. From these figures, the positive effects of the two SFCLs can be observed. In the case of without the SFCL, the main network will sell an amount of active power and reactive power to the main network under the fault, and the power fluctuations will be very obvious. Along with the increase of the SFCLs' current-limiting parameters, the exchange power will be reduced to be lower than the normal level. Since the power Load 1 is shorted, the decrease of the exchange power and the full utilization of the local DG units can help to achieve the power balance. In addition, 
taking the enhancement of the micro-grid's frequency stability as an example, employing the SFCLs can make the fluctuating margin of the micro-grid frequency limited within $0.11 \mathrm{~Hz}$, compared to it rising to $0.62 \mathrm{~Hz}$ under the condition without the SFCL.

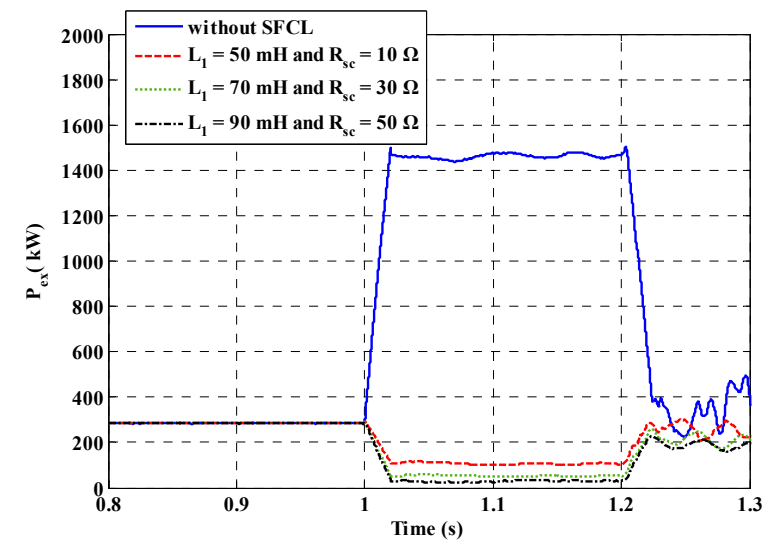

Figure 17. Active power of the micro-grid at the PCC under the internal fault.

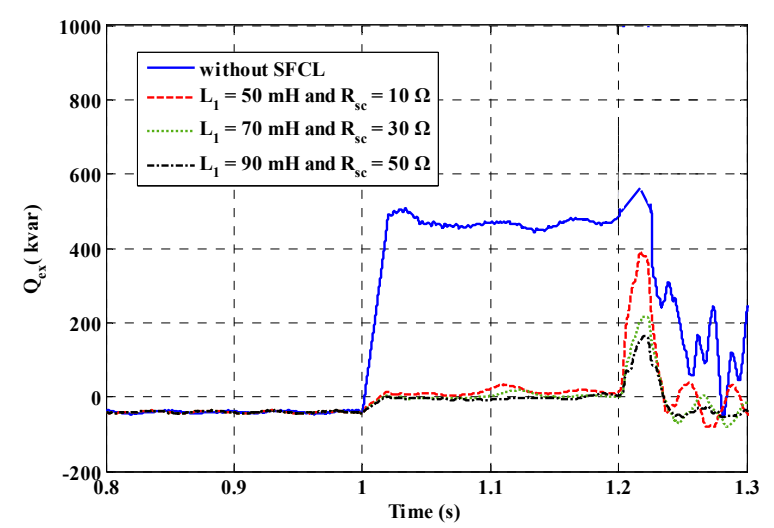

Figure 18. Reactive power of the micro-grid at the PCC under the internal fault.

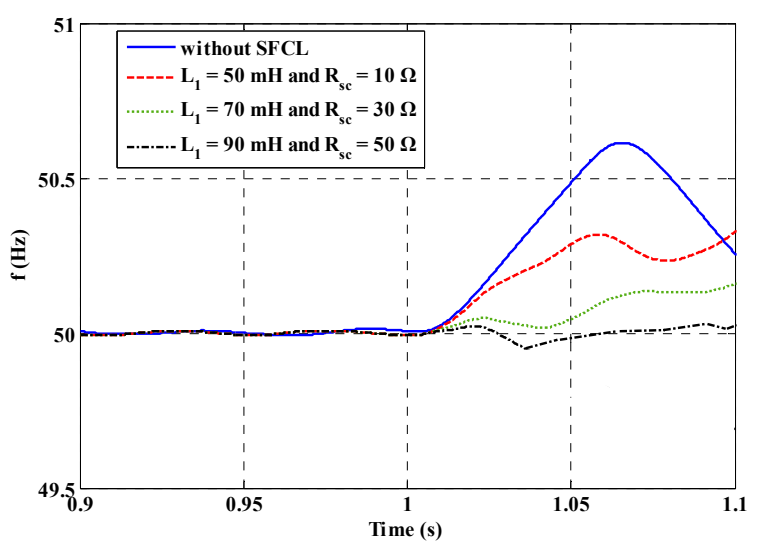

Figure 19. Frequency fluctuations of the micro-grid under the internal fault.

In a similar way, the calculation results of the three evaluation sub-functions are shown in Table 4, and the analysis results of the integrated technical evaluation function under different weighting factors are shown in Table 5. For the weightings set as $w_{1}=0.3, w_{2}=0.3, w_{3}=0.4$, the current-limiting parameters of $L_{1}=70 \mathrm{mH}$ and $R_{\mathrm{sc}}=30 \Omega$ can be regarded as the most suitable of the three demonstrative schemes. 
Table 4. Calculation results of the three evaluation sub-functions under different current-limiting parameters (internal fault).

\begin{tabular}{cccc}
\hline \multirow{2}{*}{ Current-Limiting Parameters } & \multicolumn{3}{c}{ Evaluation Sub-Functions } \\
\cline { 2 - 4 } & $\boldsymbol{J}_{\mathbf{1}}$ & $\boldsymbol{J}_{\mathbf{2}}$ & $\boldsymbol{J}_{\mathbf{3}}$ \\
\hline$L_{1}=50 \mathrm{mH}$ and $R_{\mathrm{sc}}=10 \Omega$ & 18.9939 & 34.412 & 13.5096 \\
$L_{1}=70 \mathrm{mH}$ and $R_{\mathrm{Sc}}=30 \Omega$ & 11.4116 & 26.848 & 21.2448 \\
$L_{1}=90 \mathrm{mH}$ and $R_{\mathrm{sc}}=50 \Omega$ & 10.7163 & 23.855 & 28.8598 \\
\hline
\end{tabular}

Table 5. Calculation results of the integrated technical evaluation function under different weighting factors (internal fault).

\begin{tabular}{ccccc}
\hline & \multicolumn{3}{c}{ Integrated Technical Evaluation Function $\left(J_{\text {int-eva }}\right)$} \\
\cline { 2 - 5 } Current-Limiting & $\boldsymbol{w}_{\mathbf{1}}=\mathbf{0 . 1}$, & $\boldsymbol{w}_{\mathbf{1}}=\mathbf{0 . 1}$, & $\boldsymbol{w}_{\mathbf{1}}=\mathbf{0 . 8}$, & $\boldsymbol{w}_{\mathbf{1}}=\mathbf{0 . 3}$, \\
Parameters & $\boldsymbol{w}_{\mathbf{2}}=\mathbf{0 . 1}$, & $\boldsymbol{w}_{\mathbf{2}}=\mathbf{0 . 8}$, & $\boldsymbol{w}_{\mathbf{2}}=\mathbf{0 . 1}$, & $\boldsymbol{w}_{\mathbf{2}}=\mathbf{0 . 3}$, \\
& $\boldsymbol{w}_{\mathbf{3}}=\mathbf{0 . 8}$ & $\boldsymbol{w}_{\mathbf{3}}=\mathbf{0 . 1}$ & $\boldsymbol{w}_{\mathbf{3}}=\mathbf{0 . 1}$ & $\boldsymbol{w}_{\mathbf{3}}=\mathbf{0 . 4}$ \\
\hline$L_{1}=50 \mathrm{mH}$ and $R_{\mathrm{SC}}=10 \Omega$ & 16.1481 & 30.77835 & 19.9871 & 21.425 \\
$L_{1}=70 \mathrm{mH}$ and $R_{\mathrm{SC}}=30 \Omega$ & 20.8218 & 24.744 & 13.9386 & 19.9758 \\
$L_{1}=90 \mathrm{mH}$ and $R_{\mathrm{Sc}}=50 \Omega$ & 26.545 & 23.0415 & 13.8445 & 21.9153 \\
\hline
\end{tabular}

\section{Conclusions}

In this paper, the fault characteristics of the micro-grid system including distributed generation, energy storage and power loads are analyzed, and further, a technical evaluation method considering current-limiting performance, bus voltage stability and device cost is proposed for the application of one or more SFCLs. According to the modeling and simulations of a $10-\mathrm{kV}$ micro-grid system under external and internal faults, the results show that:

(1) The current, voltage and power of the micro-grid and DG units will be dramatically affected under the fault, and the SFCL can be installed at the integration point of the DG units or the transmission line for the protection of the DG or the power load. In addition, the SFCL can be selectively installed at the PCC for the protection of the entire micro-grid.

(2) Regarding the specific performance behaviors, the efficient use of the SFCLs can contribute to reducing the fault current, improving the voltage sags and suppressing the frequency fluctuations. For different current-limiting parameters of the SFCLs, the technical evaluation and quantitative comparison are done in detail.

(3) There will be a compromise design to fully take advantage of the performance of the SFCLs' current-limiting parameters, and thus, the micro-grid's transient performance under fault conditions can be guaranteed. This conclusion will be effective when the three weightings for the evaluation sub-functions have similar values or have a little difference, and in general, it may not be recommended to excessively emphasize a certain weighting since the other weightings will lose their importance and significance.

(4) If the proposed technical evaluation function is used to optimally select and place the SFCLs in the micro-grid, the optimization objective is to make the integrated function value be the smallest, and the SFCLs' current-limiting impedances, access locations and installation quantities will be constrained by certain conditions. Due to the use of a certain intelligent algorithm, the optimization results can be theoretically obtained. In a word, the technical evaluation function can lay a foundation for the future optimal application.

In the near future, some follow-up work will be performed to promote the application of the flux-coupling-type SFCLs in a cluster of micro-grid systems, such as the SFCLs' optimization design and allocation, and the coordinated action taking into account the self-adaptive relay protection. Considering the rapid development of renewable energy systems, the highly efficient utilization of SFCLs may be regarded as a feasible solution to deal with the potential fault transient issues, and the related results will be reported in later articles. 
Acknowledgments: This work was supported in part by the National Natural Science Foundation of China (51507117), the Fundamental Research Funds for the Central Universities (2042014kf0011), the Natural Science Foundation of Hubei Province of China (2014CFB706) and the Wuhan Planning Projects of Science and Technology (2013072304010827).

Author Contributions: Lei Chen helped to design the study, analyze the data and write the manuscript. Xiude Tu helped conduct the literature survey and simulation analysis. Hongkun Chen helped conduct the study. Jun Yang helped analyze the data. Yayi Wu helped draw the figures. Xin Shu helped draft the manuscript. Li Ren helped edit the manuscript.

Conflicts of Interest: The authors declare no conflict of interest.

\section{References}

1. Obara, S. Control of cyclic fluctuations in an independent microgrid by an SOFC triple combined cycle inertia system. Int. J. Electr. Power Energy Syst. 2015, 68, 89-102. [CrossRef]

2. Jayawardena, A.V.; Meegahapola, L.G.; Robinson, D.A.; Perera, S. Microgrid capability diagram: A tool for optimal grid-tied operation. Renew. Energy 2015, 74, 497-504. [CrossRef]

3. Aryani, D.R.; Song, H. Coordination control strategy for ac/dc hybrid microgrids in stand-alone mode. Energies 2016, 9, 469. [CrossRef]

4. Lu, X.; Wan, J. Modeling and control of the distributed power converters in a standalone dc microgrid. Energies 2016, 9, 217. [CrossRef]

5. Lin, W.M.; Tu, C.S.; Tsai, M.Y. Energy management strategy for microgrids by using enhanced bee colony optimization. Energies 2016, 9, 5. [CrossRef]

6. Abedini, M.; Moradi, M.H.; Hosseinian, S.M. Optimal management of microgrids including renewable energy scources using GPSO-GM algorithm. Renew. Energy 2016, 90, 430-439. [CrossRef]

7. Xie, S.; Wang, Y. Construction of tree network with limited delivery latency in homogeneous wireless sensor networks. Wireless Pers. Commun. 2014, 78, 231-246. [CrossRef]

8. Guo, P.; Wang, J.; Li, B.; Lee, S. A variable threshold-value authentication architecture for wireless mesh networks. J. Internet Technol. 2014, 15, 929-936.

9. Ren, Y.; Shen, J.; Wang, J.; Han, J.; Lee, S. Mutual verifiable provable data auditing in public cloud storage. J. Internet Technol. 2015, 16, 317-323.

10. Fu, Z.; Sun, X.; Liu, Q.; Zhou, L.; Shu, J. Achieving efficient cloud search services: multi-keyword ranked search over encrypted cloud data supporting parallel computing. IEICE Trans. Commun. 2015, 98, 190-200. [CrossRef]

11. Xia, Z.; Wang, X.; Sun, X.; Wang, Q. A secure and dynamic multi-keyword ranked search scheme over encrypted cloud data. IEEE Trans. Parallel Distr. Syst. 2015, 27, 340-352. [CrossRef]

12. Yan, B.; Wang, B.; Zhu, L.; Liu, H.; Liu, Y.; Ji, X.; Liu, D. A novel, stable, and economic power sharing scheme for an autonomous microgrid in the energy internet. Energies 2015, 8, 12741-12764. [CrossRef]

13. Yuan, C.; Sun, X.; Lv, R. Fingerprint liveness detection based on multi-scale LPQ and PCA. China Commun. 2016, 13, 60-65. [CrossRef]

14. Lee, J.G.; Khan, U.A.; Hwang, J.S.; Seong, J.K.; Shin, W.J.; Park, B.B.; Lee, B.W. Assessment on the influence of resistive superconducting fault current limiter in VSC-HVDC system. Physica C 2014, 504, 163-166. [CrossRef]

15. Firouzi, M.; Gharehpetian, G.B.; Mozafari, B. Bridge-type superconducting fault current limiter effect on distance relay characteristics. Int. J. Electr. Power Energy Syst. 2015, 68, 115-122. [CrossRef]

16. Chen, L.; Li, Z.; Deng, C.; Liu, H.; Weng, Y.; Xu, Q.; Wu, Z.; Tang, Y. Effects of a flux-coupling-type superconducting fault current limiter on the surge current caused by closed-loop operation in a $10 \mathrm{kV}$ distribution network. Int. J. Electr. Power Energy Syst. 2015, 69, 160-166. [CrossRef]

17. Xue, S.; Gao, F.; Sun, W.; Li, B. Protection Principle for a DC distribution system with a resistive superconductive fault current limiter. Energies 2015, 8, 4839-4852. [CrossRef]

18. Oliveira, F.; Amorim, A.; Encarnação, L.; Fardin, J.; Orlando, M.; Silva, S.; Simonetti, D. Enhancing LVRT of DFIG by using a superconducting current limiter on rotor circuit. Energies 2016, 9, 16. [CrossRef]

19. Colmenar-Santos, A.; Pecharromán-Lázaro, J.M.; de Palacio Rodríguez, C.; Collado-Fernández, E. Performance analysis of a superconducting fault current limiter in a power distribution substation. Electr. Power Syst. Res. 2016, 136, 89-99. [CrossRef] 
20. Ebrahimpour, M.; Vahidi, B.; Hosseinian, S.H. A hybrid superconducting fault current controller for DG networks and microgrids. IEEE Trans. Appl. Supercond. 2013, 23, 5604306. [CrossRef]

21. Khan, U.; Seong, J.; Lee, S.; Lim, S.; Lee, B. Feasibility analysis of the positioning of superconducting fault current limiters for the smart grid application using simulink and simpowersystem. IEEE Trans. Appl. Supercond. 2011, 21, 2165-2169. [CrossRef]

22. Hwang, J.; Khan, U.; Shin, W.; Seong, J.; Lee, J.; Kim, Y.; Lee, B. Validity analysis on the positioning of superconducting fault current limiter in neighboring AC and DC microgrid. IEEE Trans. Appl. Supercond. 2013, 23, 5600204. [CrossRef]

23. Zheng, F.; Deng, C.; Chen, L.; Li, S.; Liu, Y.; Liao, Y. Transient performance improvement of microgrid by a resistive superconducting fault current limiter. IEEE Trans. Appl. Supercond. 2015, 25, 5602305. [CrossRef]

24. Chen, L.; Zheng, F.; Deng, C.; Li, S.; Li, M.; Liu, H.; Zhu, L.; Guo, F. Application of a modified flux-coupling-type superconducting fault current limiter to transient performance enhancement of micro-grid. Physica C 2015, 518, 144-148. [CrossRef]

25. Ghanbari, T.; Farjah, E. Development of an efficient solid-state fault current limiter for microgrid. IEEE Trans. Power Deliv. 2012, 27, 1829-1834. [CrossRef]

26. Ghanbari, T.; Farjah, E. Unidirectional fault current limiter: An efficient interface between the microgrid and main network. IEEE Trans. Power Syst. 2013, 28, 1591-1598. [CrossRef]

27. Ghanbari, T.; Farjah, E. A multiagent-based fault-current limiting scheme for the microgrids. IEEE Trans. Power Deliv. 2014, 29, 525-533. [CrossRef]

28. Cheng, M.; Zhu, Y. The state of the art of wind energy conversion systems and technologies: A review. Energy Convers. Manag. 2014, 88, 332-347. [CrossRef]

29. Arribas, J.R.; Rodríguez, A.F.; Muñoz, Á.H. Low voltage ride-through in DFIG wind generators by controlling the rotor current without crowbars. Energies 2014, 7, 498-519. [CrossRef]

30. Le, V.; Li, X.; Li, Y.; Dong, T.L.T.; Le, C. An innovative control strategy to improve the fault ride-through capability of DFIGs based on wind energy conversion systems. Energies 2016, 9, 69. [CrossRef]

31. Hossain, M.K.; Ali, M.H. Transient stability augmentation of PV/DFIG/SG-based hybrid power system by parallel-resonance bridge fault current limiter. Electr. Power Syst. Res. 2016, 130, 89-102. [CrossRef]

32. Chen, L.; Deng, C.; Zheng, F.; Li, S.; Liu, Y.; Liao, Y. Fault ride-through capability enhancement of DFIG-based wind turbine with a flux-coupling-type SFCL employed at different locations. IEEE Trans. Appl. Supercond. 2015, 25, 5201505. [CrossRef]

33. Deng, C.; Zheng, F.; Chen, L.; Li, M.; Xia, P.; Li, S.; Long, Z.; Zhu, L.; Guo, F. Study of a modified flux-coupling-type superconducting fault current limiter for mitigating the effect of DC short circuit in a VSC-HVDC system. J. Supercond. Nov. Magn. 2015, 28, 1525-1534. [CrossRef]

34. Chen, L.; Tang, Y.; Li, Z.; Ren, L.; Shi, J.; Cheng, S. Current limiting characteristics of a novel flux-coupling type superconducting fault current limiter. IEEE Trans. Appl. Supercond. 2010, 20, 1143-1146. [CrossRef]

35. Ren, L.; Tang, Y.; Li, Z.; Chen, L.; Shi, J.; Jiao, F.; Li, J. Techno-economic evaluation of a novel flux-coupling type superconducting fault current limiter. IEEE Trans. Appl. Supercond. 2010, 20, 1242-1245. [CrossRef]

36. Chen, L.; Pan, H.; Deng, C.; Zheng, F.; Li, Z.; Guo, F. Study on the application of a flux-coupling-type superconducting fault current limiter for decreasing HVDC commutation failure. Can. J. Elect. Comput. Eng. 2015, 38, 10-19. [CrossRef]

37. Didier, G.; Bonnard, C.H.; Lubin, T.; Lévêque, J. Comparison between inductive and resistive SFCL in terms of current limitation and power system transient stability. Elect. Power Syst. Res. 2015, 125, 150-158. [CrossRef]

38. Kou, W.; Wei, D.; Zhang, P.; Xiao, W. A direct phase-coordinates approach to fault ride through of unbalanced faults in large-scale photovoltaic power systems. Electr. Power Compon. Syst. 2015, 43, 902-913. [CrossRef]

39. Yang, Y.; Enjeti, P.; Blaabjerg, F.; Wang, H. Suggested grid code modifications to ensure wide-scale adoption of photovoltaic energy in distributed power generation systems. In Proceedings of the 2013 IEEE Industry Applications Society Annual Meeting, Lake Buena Vista, FL, USA, 6-11 Octber 2013; pp. 1-8.

40. Lopez, J.; Sanchis, P.; Roboam, X.; Marroyo, L. Dynamic behavior of the doubly fed induction generator during three-phase voltage dips. IEEE Trans. Energy Convers. 2007, 22, 709-717. [CrossRef]

41. Surour, A.; Ahmed, M.; Mohamed, S.; Vinod, K. Voltage booster schemes for fault ride-through enhancement of variable speed wind turbines. IEEE Trans. Sustain. Energy 2013, 4, 1071-1081. 
42. Zeng, D.; Pan, G.; Wang, G.; Zhu, G.; Cai, Y. Method of fault analysis on microgrid with distributed generation based on V/f control strategy. Proc. CSEE 2014, 34, 2604-2611.

43. Milanovic, J.V.; Aung, M.T.; Vegunta, S.C. The influence of induction motors on voltage sag propagation-Part II: Accounting for the change in sag performance at LV buses. IEEE Trans. Power Deliv. 2008, 23, 1072-1078. [CrossRef]

44. Alaboudy, A.; Zeineldin, H.; James, L. Microgrid stability characterization subsequent to fault-triggered islanding incidents. IEEE Trans. Power Deliv. 2012, 27, 658-669. [CrossRef]

45. Chen, B.; Wei, L.; Lei, Y.; Tu, Y.; Yuan, J.; Chen, F.; Lie, D.; Pan, J. Immune algorithm based pareto multi-objective optimal allocation of high temperature superconductor-fault current limiters. Power Syst. Technol. 2015, 39, 1343-1350.

46. Qian, K.; Yuan, Y.; Shi, X.; Zhou, C.; Ju, P. Environmental benefits analysis of distributed generation. Proc. CSEE 2008, 28, 11-15.

47. Moon, J.F.; Lim, S.H.; Kim, J.C.; Yun, S.Y. Assessment of the impact of SFCL on voltage sags in power distribution system. IEEE Trans. Appl. Supercond. 2011, 21, 2161-2164. [CrossRef]

48. Muyeen, S.M.; Takahashi, R.; Murata, T.; Tamura, J.; Al, M.H.; Matsumura, Y.; Kuwayama, A.; Matsumoto, T. Low voltage ride through capability enhancement of wind turbine generator system during network disturbance. IET Renew. Power Gener. 2009, 3, 65-74. [CrossRef]

49. Yang, Y.; Blaabjerg, F.; Zou, Z. Benchmarking of grid fault modes in single-phase grid-connected photovoltaic systems. IEEE Trans. Ind. Appl. 2013, 49, 2167-2176. [CrossRef]

50. Mahat, P.; Chen, Z.; Birgitte, B.; Claus, L. A simple adaptive overcurrent protection of distribution systems with distributed generation. IEEE Trans. Smart Grid 2011, 2, 428-437. [CrossRef]

51. Li, B.; Li, C.; Guo, F.; Xin, Y. Overcurrent protection coordination in a power distribution network with the active superconductive fault current limiter. IEEE Trans. Appl. Supercond. 2014, 24, 5602004.

52. Bakar, A.; Ooi, B.; Govindasamy, P.; Tan, C.; Illias, H.; Mokhlis, H. Directional overcurrent and earth-fault protections for a biomass microgrid system in Malaysia. Int. J. Electr. Power Energy Syst. 2014, 55, 581-591. [CrossRef]

53. Yuan, G.; Chen, S.; Wang, L. Economic optimal dispatch of virtual power plant considering environmental benefits. Adv. Renew. Energy 2015, 3, 398-404.

54. Liu, G.; Yuan, Y.; Wang, M.; Dai, X.; Xu, L. Energy storage capacity determining of PV plant considering economic cost. Renew. Energy Res. 2014, 32, 1-5. [CrossRef]

55. Faria, P.; Soares, J.; Vale, Z.; Morais, H.; Sousa, T. Modified particle swarm optimization applied to integrated demand response and DG resources scheduling. IEEE Trans. Smart Grid 2013, 4, 606-616. [CrossRef]

56. Xiao, Y.; Zhang, T.; Ding, Z.; Li, C. The study of fuzzy proportional integral controllers based on improved particle swarm optimization for permanent magnet direct drive wind turbine converters. Energies 2016, 9, 343. [CrossRef]

57. Huang, M.L. Hybridization of chaotic quantum particle swarm optimization with SVR in electric demand forecasting. Energies 2016, 9, 426. [CrossRef]

(C) 2016 by the authors; licensee MDPI, Basel, Switzerland. This article is an open access article distributed under the terms and conditions of the Creative Commons Attribution (CC-BY) license (http://creativecommons.org/licenses/by/4.0/). 